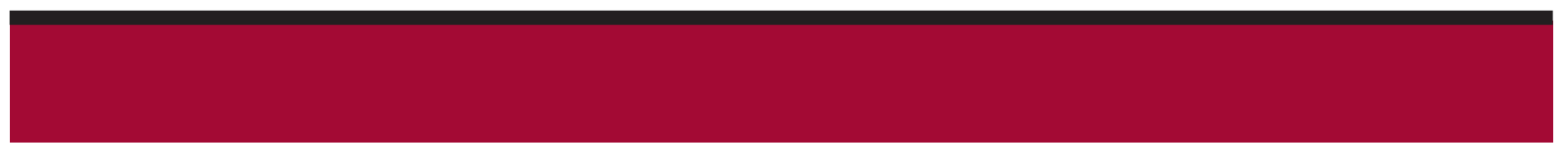

\section{Payment for Performance and the QOF: are we doing the right thing?}

The authors seem to work under the assumption that there is a payment system for GPs that will not create a conflict of interest, but I do not believe that this is the case: every payment system will have some negative impact on GPs behaviour: capitation based systems incentivise huge lists with little actual care, while systems that pay GPs for activity (such as, for example, in Germany or the US), create a bias towards 'activism', in other words, arranging lots of tests and investigations and discourage spending time with patients for histories, examination findings, and explanations. Systems that pay every GP the same salary las in Cuba or the former Soviet Union) are known to discourage doctors and can either lead to disengagement or to parallel earnings from private practice or non-medical activities.

Let's face it: GPs are only human, and collectively will behave as humans do, and a good majority will always be motivated by financial gain - this doesn't necessarily have to be selfish as such, but pressure to provide well for children and other dependants creates incentives of its own.

It can be argued that QOF could minimise the conflict of interest between professionalism and financial interest, by increasing pay for good practice and decreasing it for bad practice.

That this can't always work perfectly is obvious, and one way to address this is to constantly adjust it, keeping indicators that seem to perform well and removing those that encourage 'gaming'.

What worries me is that there is no systematic way of gathering opinion from working GPs as to which indicators perform well: every self-respecting GP knows which of the indicators motivate us to improve evidence-based care (in my opinion, asthma reviews, blood pressure targets, epilepsy reviews, and several others meet this), and which ones encourage 'gaming' lone of the worst, in my view, being $P H Q-9$ for depression).

Why are jobbing GPs not more involved in developing QOF?

Gerda Pohl,
The Market Surgery, Warehouse Lane, South Yorkshire, S63 7RA.

E-mail: gerda.pohlaphaseworldwide.org

\section{Competing interests}

In our practice, I am nominally responsible for the depression indicators, but we have given up trying to achieve them.

\section{REFERENCE}

1. Kramer G. Payment for Performance and the QOF: are we doing the right thing? Br J Gen Pract 2012; DOI: 10.3399/bjgp12X630151.

DOI: 10.3399/bjgp12X641401

\section{Communicating risk to patients and the public}

Despite years of trying to communicate risk to patients and months of reading about it recently, I found this article confusing, because it fails to address a fundamental question 'what is the aim of communicating risk?'

The authors refer to two possible aims of communicating risk. The first is to facilitate a shared, evidence-based decision that both Mrs Jones and her doctor may be satisfied about'. The second is 'to promote risk reduction through behaviour change'. They do not mention the tension between these, but it has been discussed by several authors including Gupta; ${ }^{2}$ some of those studying evidence-based decision-making, including Professor Edwards, ${ }^{3}$ state that the primary goal of any doctor-patient interaction is the facilitation of evidencebased choice, even where this leads the patient to decide not to follow medical advice, a stance supported in the NICE guidance on adherence. ${ }^{4}$ This tension seems widely ignored by those working to achieve behaviour change, who therefore advocate choosing the most 'persuasive' risk representation format. A clear example of the conflict between these aims lies in the controversy over decision aids for bowel cancer screening, where Bekker's 'informed uptake' 5 was Penston's 'propaganda.'.

Naik et al imply that their first priority is 'informed decision-making' and a focus on 'the individual patient'. However, they describe improving adherence as crucial, without acknowledging any difficulty in reconciling this aim with their first one, and they refer predominantly to the behaviour change literature.
Without a defined aim, methods of communicating risk cannot be judged or ranked: the paper's references to effectiveness beg the question 'what effect do we want?' The Cochrane review of decision aids referred to, and its more recent update, ${ }^{7}$ looked at a wide range of assessable outcomes and concluded that there was some improvement in measures of decision quality, no effect on health outcomes or anxiety, and inconclusive evidence about adherence. A recent study by Gale et al illustrates this, finding that even a demonstrably successful healthliteracy-promoting intervention about cardiovascular risk made no difference to whether or not subjects chose to take tablets, ${ }^{8}$ although many welcomed the increased involvement and informedness they gained.

The key question is whether, and how, people make use of risk information once they have understood it, and there is a growing body of evidence about this. In order to contribute to analysis of this evidence, a future paper on risk communication should begin with a debate about its aims.

\section{Louisa Polak}

Research Student, London School of Hygiene and Tropical Medicine.

E-mail: louisa.polakalshtm.ac.uk

\section{REFERENCES}

1. Naik G, Ahmed H, Edwards AGK. Communicating risk to patients and the public. Br J Gen Pract 2012; 62(597): 213-216

2. Gupta M. Improved health or improved decision making? The ethical goals of EBM. J Eval Clin Pract 2011; 17(5): 957-963.

3. Edwards A, Elwyn G. Risks - listen and don't mislead. Br J Gen Pract 2001; 51(465): 259-260.

4. NICE. Medicines adherence. London: NICE, 2009.

5. Bekker HL. Decision aids and uptake of screening. BMJ 2010; 341: c5407.

6. Penston J. Beware next wave of propaganda. BMJ 2011; 342: d3369.

7. Stacey D, Bennett CL, Barry MJ, et al. Decision aids for people facing health treatment or screening decisions. Cochrane Database Syst Rev 2011; (10): CD001431.

8. Gale NK, Greenfield S, Gill P, et al. Patient and general practitioner attitudes to taking medication to prevent cardiovascular disease after receiving detailed information on risks and benefits of treatment: a qualitative study. BMC Fam Pract 2011; 12: 59

DOI: 10.3399/bjgp12X641410 